\title{
Plasma immersion ion implantation (PIII) influence on Ti-6Al-4V alloy: Frequency effect
}

\author{
V.M.C.A. Oliveira ${ }^{a, *}$, M.O.H. Cioffi ${ }^{\mathrm{a}}$, M.J.R. Barboza ${ }^{\mathrm{b}}$, R. Landers ${ }^{\mathrm{c}}$, B. Schmitt ${ }^{\mathrm{d}}$, D.C.A.R. Tapia ${ }^{\mathrm{e}}$, \\ H.J.C. Voorwald ${ }^{\mathrm{a}}$ \\ a Faculdade de Engenharia de Guaratinguetá - UNESP, Brazil \\ ${ }^{\mathrm{b}}$ Escola de Engenharia de Lorena - USP, Brazil \\ "Instituto de Física "Gleb Wataghin" - UNICAMP, Brazil \\ ${ }^{\mathrm{d}}$ Faculty of Engineering Science - Universität Bayreuth, Germany \\ e Universidad Nacional de Ingenieria - UNI, Peru
}

A R T I C L E I N F O

\section{Keywords:}

Ti-6Al-4V alloy

PIII treatment

Frequency

Axial fatigue

\begin{abstract}
A B S T R A C T
The plasma immersion ion implantation treatment (PIII) acts to increase mechanical resistance with solid solution formation, new phases and defects inclusion, besides chemical and residual stress profile modification. Ti$6 \mathrm{Al}-4 \mathrm{~V}$ alloy presents poor tribological properties and high affinity with interstitial elements, such as nitrogen and oxygen, this makes it more reactive at high temperatures. This paper aims to study Ti-6Al-4V alloy fatigue behavior subjected to nitrogen addition by plasma immersion ion implantation. It was investigated the frequency parameter influence on fatigue resistance. Ti-6Al-4V alloy was PIII treated with voltage equal to $9.5 \mathrm{kV}$, frequencies varying between 1000 and $1500 \mathrm{~Hz}$ and submitted to axial fatigue tests. Axial fatigue tests were performed, at room temperature and $\mathrm{R}=0.1$. Ti-6Al-4V alloy fatigue results were supported by Weibull statistics analysis. Ti-6Al-4V alloy microstructural analysis showed equiaxed $\alpha+\beta$ grains. Weibull analysis at untreated condition presented $\mathrm{m}$ values greater than 1, indicating reliability and uniformity. For a lifetime of $10^{7}$ cycles, fatigue resistance was equal to $829 \mathrm{MPa}$ for untreated condition, 644,767 and $417 \mathrm{MPa}$, for $f=1000,1200$ and $1500 \mathrm{~Hz}$, respectively. The nitrogen-based compounds were detected only at the condition where $f=1200 \mathrm{~Hz}$. Thus, the combination of PIII treatment parameters, when $f=1200 \mathrm{~Hz}$, hindered crack nucleation and increasing fatigue resistance of treated Ti-6Al-4V alloy when compared with the other two treatment conditions.
\end{abstract}

\section{Introduction}

The plasma immersion ion implantation treatment (PIII) modifies complex surfaces without varying piece dimensions, works at a wide temperature range and enables the formation of non-balance phases and structures. Additionally, its implantation system has treatment times independent of sample size and can be used without special sample manipulation (even in the case of irregular surfaces) $[1,2]$. The literature reported studies where wear and creep resistance increased due to nitrogen implantation by PIII $[3,4]$. The main mechanisms that act to increase mechanical resistance are solid solution formation, new phases and defects inclusion, besides chemical and residual stress profile modification $[5,6]$. The level of residual stresses has a limit, which, above it, deform, induce cracks, or fracture the material to relief the crystalline structure [5]. The superficial modification, which means, the nitrogen penetration depends of plasma-related (composition, density, energy), pulse (frequency, size and working mode) and temperature characteristics $[7,8]$.

The Ti-6Al-4V alloy is applied in the aeronautical industry due to mechanical strength, corrosion resistance and the highest specific resistance among light alloys $[9,10]$. On the other hand, this material presents poor tribological properties and high affinity with interstitial elements, such as nitrogen and oxygen, which makes it more reactive at high temperatures [11]. Therefore, the literature presents several works that improved the surface qualities of titanium alloys without modifying its mechanical characteristics [11-14].

Lin et al. [15] treated Ti-6Al-4V alloy with nitrogen by GTAW. The authors studied the influence of nitride layer on wear resistance and concluded that GTAW treatment improved wear resistance of Ti-6Al-4V alloy. They reported that $\mathrm{TiN}$ or $\mathrm{TiN}+\mathrm{TiN}_{\mathrm{x}}$ clad layers reduced wear

\footnotetext{
* Corresponding author

E-mail address: veronicamcaoliveira@gmail.com (V.M.C.A. Oliveira).
} 

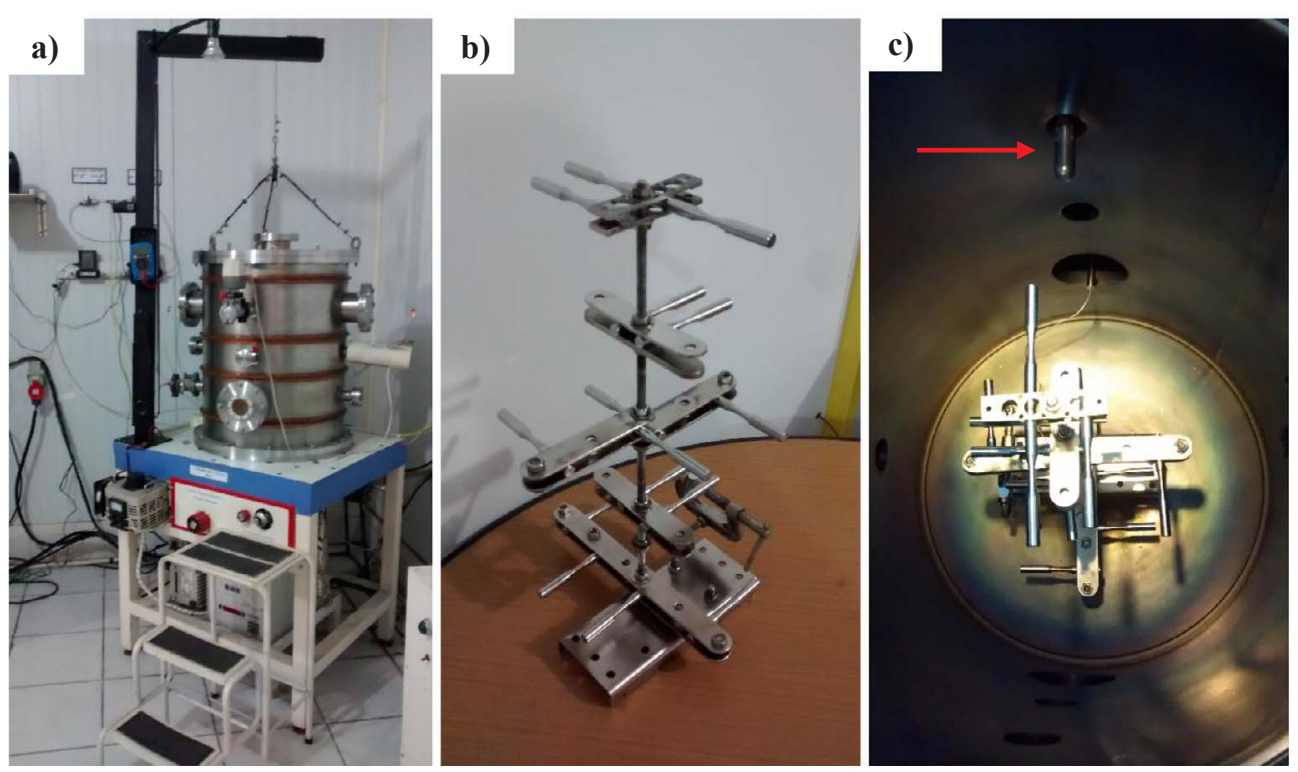

Fig. 1. Vacuum chamber: (a) general view, (b) specimen holder, (c) plasma source.

volume losses in at least 95\%. Ali and coauthors [16] studied fatigue behavior of CpTi modified by nitrogen ion implantation (Nii). They conducted experiments varying between 240 and $320 \mathrm{MPa}$ and reported better resistance to fatigue for Nii treated $\mathrm{CpTi}$, with resistance to fatigue $3.8 \%$ higher $\left(\mathrm{N}=10^{7}\right.$ cycles).

At the same time, Bonora [17] and Minto [18] reported that stainless steel and aluminum alloys treated by PIII were subjected to cyclic loading and resulted in increased fatigue resistance of the treated materials.

This work aims to study the parameter influence of the PIII treatment - frequency - on the microstructure, composition and fatigue behavior of Ti-6Al-4V alloy.

\section{Materials and methods}

Ti grade 5 was used with the same composition of Ti balance, $6 \% \mathrm{Al}$, $4 \%$ V. Scanning electron microscopy (SEM) was used to calculate grain diameter and phases proportion.

The PIII system consists of a vacuum chamber with a specimen holder, glow discharge plasma source and a high voltage pulses modulator (Fig. 1).

The cleaning step with argon is performed at a flow of $4.1 \mathrm{~cm}^{3} / \mathrm{min}$; at $10^{-3}$ mbar and with a plasma, maintained with a voltage of $5 \mathrm{kV}$ and current of $127 \mathrm{~mA}$, during $15 \mathrm{~min}$. At this point, nitrogen plasma was produced and nitrogen ions $(\mathrm{N}+)$ were accelerated towards the substrate. The working voltage was equal to $9.5 \mathrm{kV}$. The bombardment frequency varied between 1000 and $1500 \mathrm{~Hz}$, nitrogen/hydrogen ratio was $2: 1$. The PIII treatment lasted $2 \mathrm{~h}$, the average working temperature was equal to $390^{\circ} \mathrm{C}$. Treatment parameters were chosen according to the work reported by Ueda et al. [2] and Castagnet et al. [4]. The PIII chamber does not have measurement tools of oxygen contamination and of plasma density. Plasma density is controlled by means of the voltage application that is pulsed in pulses of $40 \mu$ s to avoid arc electric formation between the plasma and the substrate. The transformers system used by the vacuum chamber fails if it reaches high temperatures, so temperature had to be controlled to avoid system shutdown. In a common operation, frequency increasing would elevate the temperature due to more collisions on surface of the specimen, releasing a higher level of thermal energy. In order to avoid temperature increase with frequency, the working pressure was controlled. Table 1 shows the main parameters adopted in PIII treatments.

Vickers microhardness measurements were performed on the untreated specimen along its cross section, according to ASTM E 384. An
Table 1

Main parameters adopted in PII treatments.

\begin{tabular}{llll}
\hline Frequency (Hz) & 1000 & 1200 & 1500 \\
\hline $\mathrm{P}_{\text {Initial }}$ (mbar) & $6.5 \times 10^{-3}$ & $3.6 \times 10^{-3}$ & $6.5 \times 10^{-3}$ \\
$\mathrm{I}(\mathrm{mA})$ & 200 & 245 & 220 \\
$\mathrm{P}_{\text {work }}$ (mbar) & $2.0 \times 10^{-2}$ & $2.0 \times 10^{-2}$ & $2.9 \times 10^{-2}$ \\
$\Delta \mathrm{P}(\mathrm{mbar})$ & $1.35 \times 10^{-2}$ & $1.64 \times 10^{-2}$ & $2.25 \times 10^{-2}$ \\
$\mathrm{~T}\left({ }^{\circ} \mathrm{C}\right)$ & 380 & 390 & 384 \\
\hline
\end{tabular}

optical profilometer, Leica DCM3D model, was used to determine the average roughness parameter, $\mathrm{Ra}$. The measured area was $1.27 \times$ $0.95 \mathrm{~mm}^{2}$ and the magnification was 10 times. The surface roughness was measured before and after PIII treatment.

Axial fatigue tests were conducted until fracture or $10^{6}$ cycles, for $\mathrm{R}=0.1$ and $f=10 \mathrm{~Hz} . \mathrm{S} v s \mathrm{~N}$ curves were raised for untreated and PIII treated conditions. The axial test specimens were made according to ASTM E466 (Fig. 2). Sixty-two (62) tests were conducted under axial fatigue conditions, divided between untreated and PIII treated conditions. Data were analyzed statistically by Log-Normal and Weibull methods.

Ti-6Al-4V alloy at untreated and PIII treated conditions were characterized by XRD. The following parameters were chosen: $40 \mathrm{kV}$;

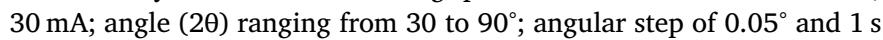
count time per point. The analysis were performed at room temperature with $\mathrm{Cu}-\mathrm{K} \alpha$ radiation and a graphite monochromator. The nitrided layer composition formed during PIII treatment was determined by XPS. XPS spectra, obtained with a VSW HA-100 hemispherical analyzer, with $\mathrm{Mg} \mathrm{K} \alpha$ radiation ( $\mathrm{hv}=1253.6 \mathrm{eV}$ ) operated in the fixed analyzer transmission mode, with a pass energy of $44 \mathrm{eV}$. The pressure during the measurements was always less than $2 \times 10^{-8}$ mbar. The specimens were fixed on a stainless steel support with double-sided conducting tape and analyzed without any further preparation.

\section{Results}

Fig. 3 shows the equiaxed grains microstructure of Ti-6Al-4V alloy.

The dark phase is $\alpha \mathrm{Ti}$ phase, the lighter one is $\beta \mathrm{Ti}$ phase. The average $\alpha$ grain diameter is $8.6 \mu \mathrm{m}$, the phases proportion is equal to $22.5 \% \beta \mathrm{Ti}$ and $77.5 \% \alpha \mathrm{Ti}$.

The average hardness value was $350 \pm 5 \mathrm{HV}$. This value is within the microhardness range values reported by Campanelli et al. [19] and Mahdipoor et al. [20]. These authors studied the mechanical properties 


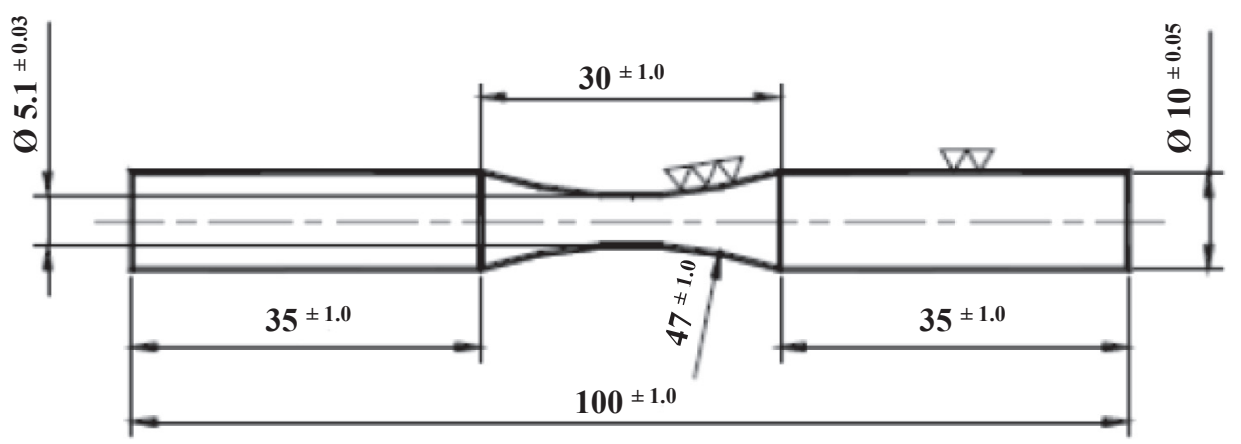

Fig. 2. Axial fatigue testing specimen.
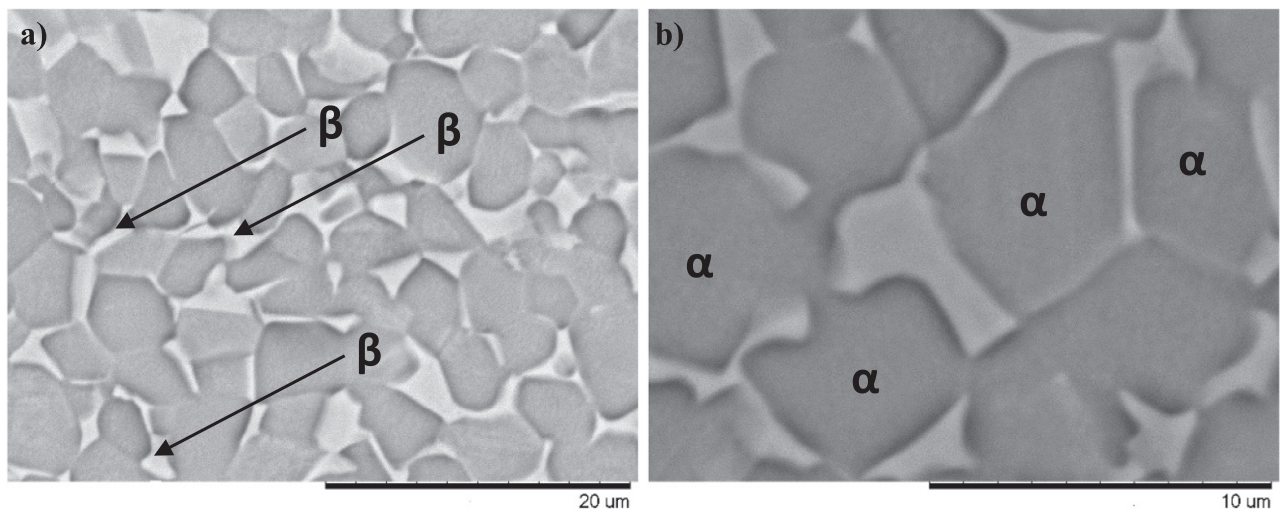

Fig. 3. SEM images of Ti-6Al-4V alloy.

of Ti-6Al-4V alloy with microstructure similar to that in the present work.

The surface roughness was measured and the results were $1.0 \mu \mathrm{m}$ for the untreated condition; for the PIII treated conditions, $1.61 \mu \mathrm{m}$ with $f=1000 \mathrm{~Hz}, 1.45 \mu \mathrm{m}$ with $f=1200 \mathrm{~Hz}$ and $1.31 \mu \mathrm{m}$ with $f=1500 \mathrm{~Hz}$. Fig. 4 shows the surface roughness variation with the adopted frequency in the PIII treatment.

Fig. 5shows the treated condition micrograph.

The $\beta$ phase was observed just below the surface. Since nitrogen is an $\alpha$ phase-stabilizing element, it could be observed that nitrogen diffusion was undetectable via microscopy analyze or negligible. In the case of diffusion reaching a few microns, it would be possible to identify an alpha phase layer just below the surface, known as alpha case.

Fig. 6 shows XPS analysis of Ti-6Al-4V alloy treated by PIII with $f=1200 \mathrm{~Hz}$.

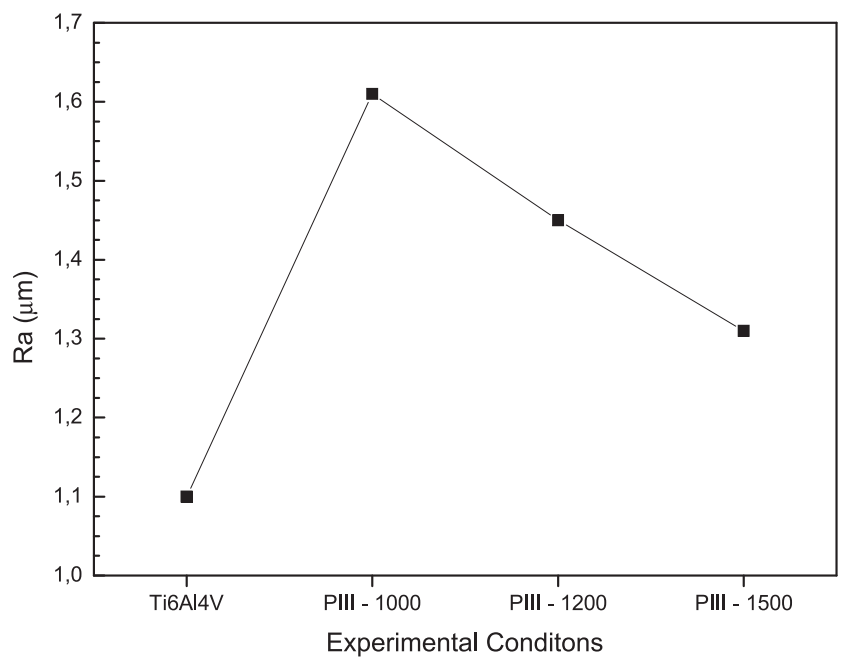

Fig. 4. Surface roughness (Ra) variation with the frequency in the PIII treatment.
Table 2 shows XPS results summary.

The binding energy of the Ti2p, N1s and O1s were used to determine the compounds on the surface. The peaks of Ti2p at 454.9 and $460.8 \mathrm{eV}$ were attributed to a TiN phase. The peak of N1s at $396.1 \mathrm{eV}$ also corresponds to the TiN phase. Peaks of Ti2p identified at 457.9 and $463.6 \mathrm{eV}$ and of O1s identified at $529.9 \mathrm{eV}$ are related to $\mathrm{TiO} 2$. Characteristic peaks of Ti2p at 455.9 and $461.4 \mathrm{eV}$, of N1s at $397.9 \mathrm{eV}$ and of $\mathrm{O} 1 \mathrm{~s}$ at $531.8 \mathrm{eV}$ are located at positions attributed to a compound of formula TiNxOy. XPS analyzes also identified carbon (C1s), aluminum (Al2p) and iron (Fe2p3/2). Carbon is associated with organic impurities on the surface, aluminum is attributed to the Ti-6Al-4V alloy composition and iron due to $\mathrm{FeO}$ formation [21]. The latter is a result of Ti-6Al-4V alloy processing and/or surface treatment. Ti-6Al-4V alloy has iron ( $\mathrm{Fe}$ ) in its composition and, through any heating step, this element segregate to the surface and react with the oxygen from the environment.

Characterization of coatings by XPS is widely reported by several studies that deposited nitrogen on metallic surfaces with different deposition techniques [22-25]. Fouquet et al. [23] studied wear behavior of Ti-6Al-4V alloy nitrided by plasma ion implantation and characterized the sample by XPS. They reported peaks of Ti2p and N1s. The binding energy ranges found in Ti2p spectra were $454.8-455.5 \mathrm{eV}$ for TiN; 456.4-457 eV for TiOxNy; and 458-458.2 eV for TiO2-x. In the N1s spectrum, the binding energies were found at $397 \mathrm{eV}$ for TiN; at $395.8 \mathrm{eV}$ for TiOxNy; and at $398 \mathrm{eV}$ for surface contaminants [23]. Oktay and colleagues [24] characterized by XPS nitride-based coatings deposited by a hybrid technique consisting of cathodic arc PVD and magnetron sputtering. XPS analysis showed Ti2p3/2 binding energy in the TiN layer, around $455 \mathrm{eV}$, tending to move towards lower energy levels as the amount of nitrogen decreased. The presence of oxygen in compounds such as oxynitrides and oxides is related to higher energy levels positions. This present study agrees with results reported by Oktay et al. [24]. Ismail et al. [25] also identified nitrogen and oxygen adsorbed on the surface.

The maximum applied stress for axial fatigue test were determined based on yield strength $\left(\sigma_{\mathrm{ys}}\right)$ and tensile strength $\left(\sigma_{\mathrm{t}}\right)$. Fig. 7 displays the 


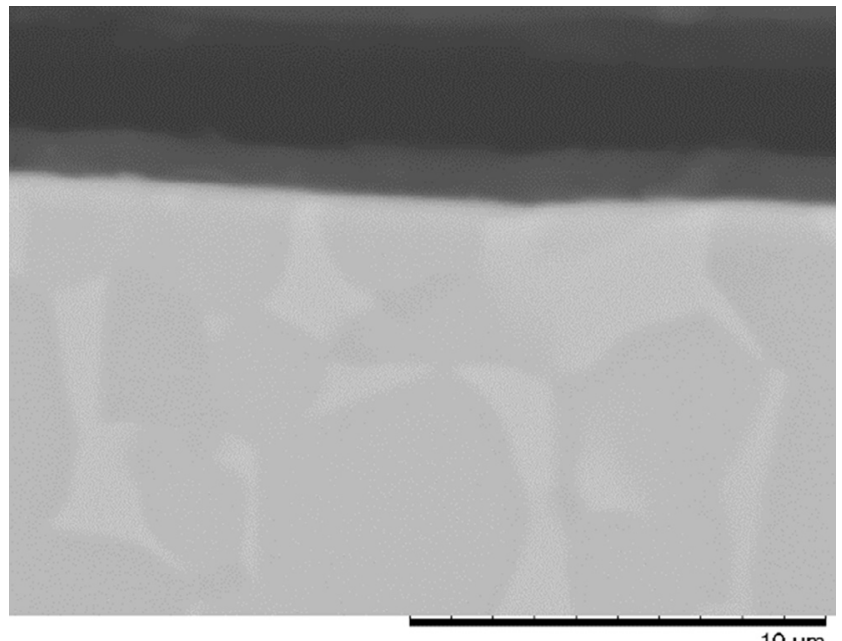

Fig. 5. PIII treated Ti-6Al-4V alloy.

S vs $\mathrm{N}$ curves of Ti-6Al-4V alloy for the untreated and PIII treated conditions, at frequencies of 1000,1200 and $1500 \mathrm{~Hz}$.

According to experimental points, showed in Fig. 3, there is indeed strong influence of frequency used in the PIII on axial fatigue strength of Ti-6Al-4V. Interesting it was observed that, after initial decrease in fatigue performance for $f=1000 \mathrm{~Hz}$, results very similar to the untreated material were obtained for $f=1200 \mathrm{~Hz}$. Therefore, tests were performed for $f=1500 \mathrm{~Hz}$ and, as shown in Fig. 3, experimental points indicated again strong decrease in fatigue strength.

For a stress of $915 \mathrm{MPa}$, untreated Ti-6Al-4V alloy reached a lifetime equal to $10^{6}$ cycles. While, for PIII treated condition, the lifetime at this same stress was equal to $3.7 \times 10^{4}, 6.3 \times 10^{4}, 1.0 \times 10^{4}$ cycles, with $f=1000,1200$ and $1500 \mathrm{~Hz}$, respectively.

According to the equations generated by the experimental data, the lifetime of $10^{7}$ cycles is related to a stress of $829 \mathrm{MPa}$ for untreated condition, which means $83 \%$ of untreated Ti6Al4V yield strength. For the PIII treated condition, the stresses related to a lifetime of $10^{7}$ are equal to 644,767 and $417 \mathrm{MPa}$, with $f=1000,1200$ and $1500 \mathrm{~Hz}$, respectively. That is 64,77 and $42 \%$ of untreated Ti6Al4V yield strength, respectively.

Costa et al. studied the Ti-6Al-4V alloy fatigue behavior superficially modified by anodizing [26] and HVOF [27] treatments. For the anodized Ti-6Al-4V alloy, with coating thickness equal to $2.50 \pm 1.27 \mu \mathrm{m}$, they reported lifetime decrease of $90 \%$ under fatigue conditions at applied stresses ranged from 955 to $985 \mathrm{MPa}$ [26]. When treated by HVOF treatment, Costa et al. [27] deposited a tungsten carbide, WC- $10 \% \mathrm{Co}-4 \% \mathrm{Cr}$, thickness and roughness values of $150 \mu \mathrm{m}$ and $2.77 \pm 0.19 \mu \mathrm{m}$, respectively. The lifetime decreased about $96 \%$ under fatigue conditions at $965 \mathrm{MPa}$. For a lifetime of 107 cycles, the maximum applied stress drop from $900 \mathrm{MPa}$ for untreated Ti-6Al-4V alloy to $400 \mathrm{MPa}$ for HVOF treated Ti-6Al-4V alloy [27].

Table 3 shows Weibull analysis distribution for each stress level in the untreated condition. The shape parameter $\mathrm{m}$ is related to material homogeneity and reliability. When $\mathrm{m}>1$, it is considered that fatigue results for a specific stress are reliable and have little variability. When $\mathrm{m}>1$, it is believed that results have high level of dispersion and, therefore, low reliability. The scale parameter $a$ supplied by Weibull distribution considers $\mathrm{x}=\mathrm{a}$ in Eq. (1).

$F_{f}(x)=1-e^{-\left(\frac{x}{a}\right)^{m}}$

When $\mathrm{x}=a, a$ means the characteristic material life that is the number of cycles, when the model evaluates fatigue resistance. Performing such replacement, it is said that $F_{f}(x)=0.632$ indicating that $63.2 \%$ of the batch of samples will fail in a certain number of
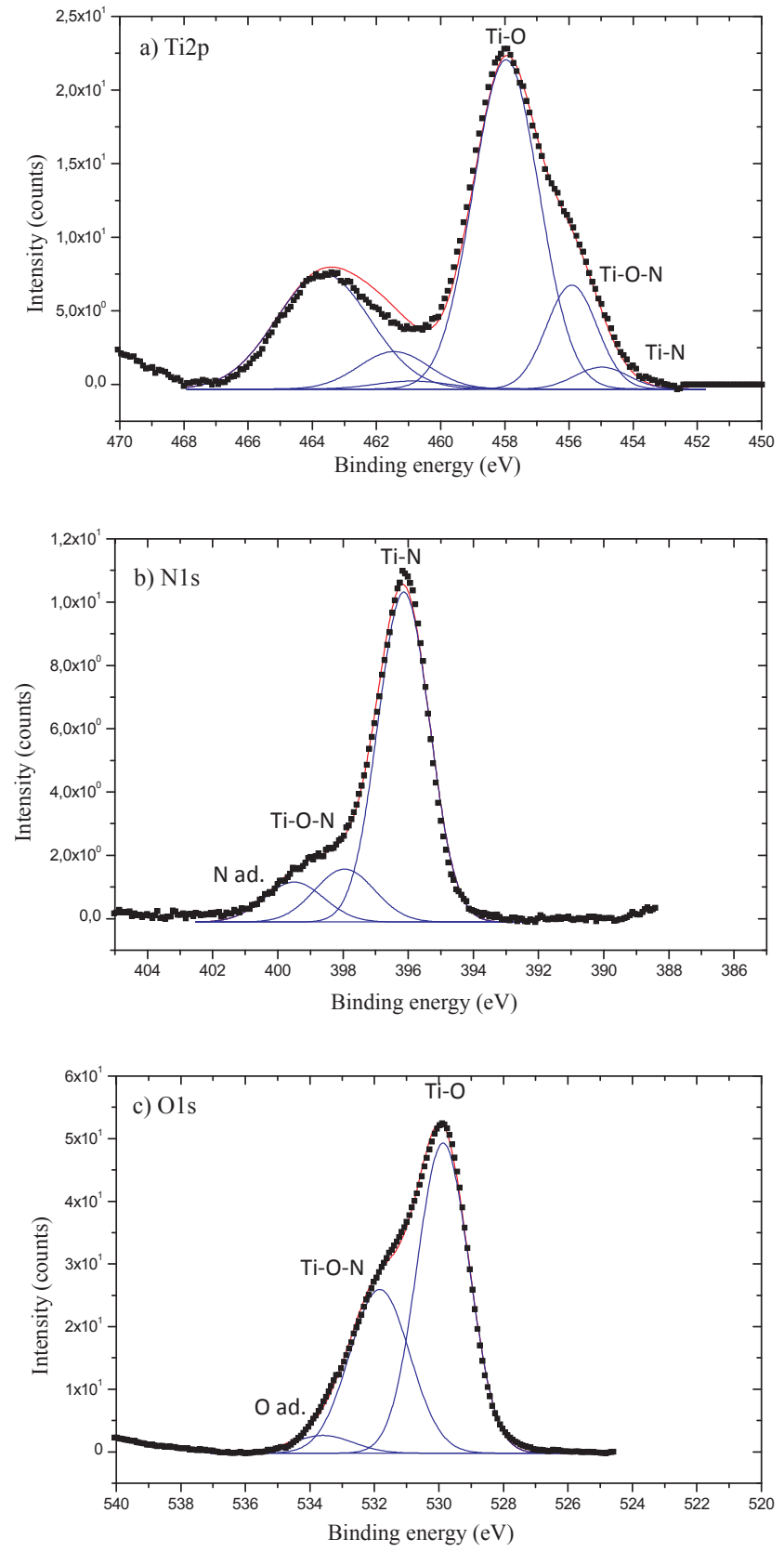

Fig. 6. XPS spectra of PIII treated Ti-6Al-4 V alloy: (a) Ti2p, (b) N1s, (c) O1s.

Table 2

XPS results summary of nitrided layer.

\begin{tabular}{llllll}
\hline & & Ti2 $_{3 / 2}$ & Ti2 $\mathrm{p}_{1 / 2}$ & N1s & \multicolumn{1}{c}{ O1s } \\
\hline \multirow{2}{*}{ Binding energy (eV) } & Ti-N & 454.9 & 460.8 & 396.1 & - \\
& Ti-O-N & 455.9 & 461.4 & 397.9 & 531.8 \\
& Ti-O & 457.9 & 463.6 & - & 529.9 \\
& N ad. & - & - & 399.5 & - \\
& O ad. & - & - & - & 533.6 \\
\hline
\end{tabular}

cycles, which was calculated by the Weibull model. If an approach in reliability terms is made, the scale parameter a can be interpreted as follows: $36.8 \%$ of the batch of samples will survive at least the number of cycles calculated by the model during fatigue process [28-30].

Table 3 shows that $m$ values for each stress level was greater than 1 , indicating reliability and uniformity, despite the apparent scattering. The curve generated by the Log-Normal model has a reliability of $50 \%$ 


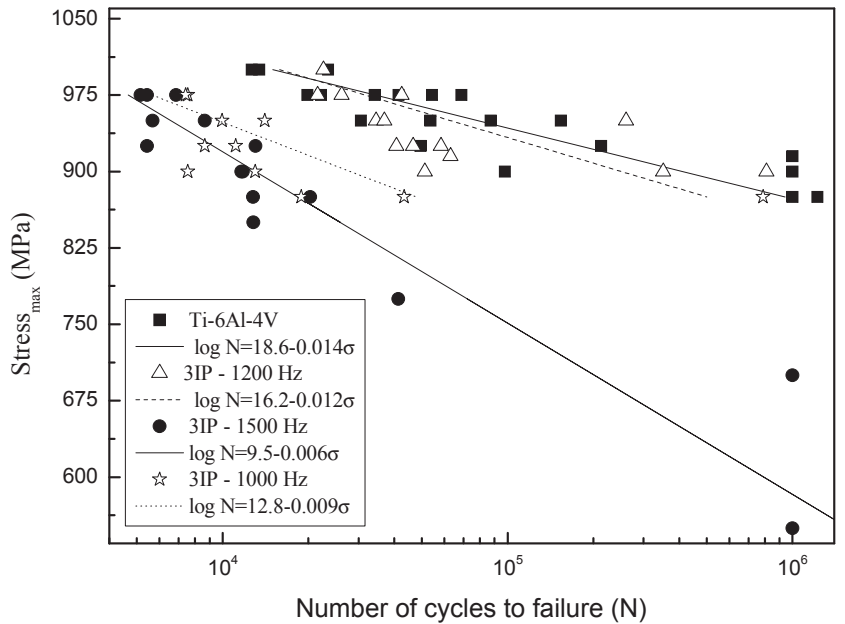

Fig. 7. $\mathrm{S} \times \mathrm{N}$ curves of Ti- $6 \mathrm{Al}-4 \mathrm{~V}$ alloy for untreated and PIII treated conditions, at frequencies of 1000,1200 and $1500 \mathrm{~Hz}$.

Table 3

Weibull analysis distribution for each 1 tension level of untreated Ti-6Al-4 V alloy .

\begin{tabular}{|c|c|c|c|c|}
\hline $\begin{array}{l}\text { Stress } \\
(\mathrm{MPa})\end{array}$ & $\% \sigma_{\mathrm{ys}}$ & Cycles (N) & $\begin{array}{l}\text { Shape parameter, } \\
\mathrm{m}\end{array}$ & $\begin{array}{l}\text { Scale parameter, } a(\mathrm{~N}) \text {, } \\
63.2 \%\end{array}$ \\
\hline 1000 & 100 & $\begin{array}{l}2.3 \times 10^{4} \\
1.3 \times 10^{4} \\
1.3 \times 10^{4}\end{array}$ & 2.45 & 19100.0 \\
\hline 975 & 97.5 & $\begin{array}{l}2.0 \times 10^{4} \\
2.2 \times 10^{4} \\
6.9 \times 10^{4} \\
5.4 \times 10^{4} \\
4.1 \times 10^{4} \\
3.4 \times 10^{4}\end{array}$ & 2.10 & 46174.4 \\
\hline 950 & 95 & $\begin{array}{l}3.1 \times 10^{4} \\
5.4 \times 10^{4} \\
1.5 \times 10^{5} \\
8.7 \times 10^{4}\end{array}$ & 1.45 & 95150.2 \\
\hline 925 & 92.5 & $\begin{array}{l}5.4 \times 10^{4} \\
2.1 \times 10^{5}\end{array}$ & 0.87 & 167662.5 \\
\hline 900 & 90 & $\begin{array}{l}9.8 \times 10^{4} \\
1.0 \times 10^{6}\end{array}$ & 0.55 & 683186.1 \\
\hline 875 & 87.5 & $\begin{array}{l}1.0 \times 10^{6} \\
1.2 \times 10^{6}\end{array}$ & 6.32 & 1183296.5 \\
\hline
\end{tabular}

according to the Weibull model.

During the PIII treatment, voltage and frequency parameters are responsible for the depth and amount of nitrogen ions collisions, respectively. The treatment temperature adopted in this study, $380 \pm 10^{\circ} \mathrm{C}$, is less than $40 \%$ of the titanium melting temperature. Therefore, the PIII treatment was carried out at low temperature. Thus, the implantation is ballistic, that means without scattering $[1,7,31]$. The diffusion, a phenomenon activated thermally, was inhibited, and the diffusion plus nitride layers formation was restricted to a few microns. Such arrangement (nitrides + diffusion layer) is common during nitriding processes conducted on titanium alloys at high temperatures ( $>550{ }^{\circ} \mathrm{C}$ ) [32]. Ballistic implantation reaches low depth values, the maximum average penetration end up at tens of nanometers, according with the implantation energy (voltage) [5]. Thus, the different treatments performed in this present study failed to build up a nitride layer, since in all three experimental cases; the implantation was of the same type (ballistic). The PIII treatments, used in this study, implanted nitrogen in depths of some interplanar distances, undetectable by microscopy, but observed by XRD. The latter was able to detect nitrides and oxides on specimen surface.

Fig. 8 shows the XRD analysis for the untreated and PIII treated conditions, at frequencies of 1000,1200 and $1500 \mathrm{~Hz}$.

Fig. 8a shows characteristic peaks of Ti6Al4V alloy in all experimental conditions. Fig. $8 \mathrm{~b}$ and $\mathrm{c}$ detail plans relating to preferred orientations of $\alpha \mathrm{Ti}, \beta \mathrm{Ti}, \mathrm{TiN}, \mathrm{Ti}_{2} \mathrm{~N}, \mathrm{TiO}_{2}$ and a compound non-stoichiometric with composition of Ti-O-N. The plans $\left(\begin{array}{llll}1 & 0 & 0\end{array}\right)\left(\begin{array}{llll}0 & 0 & 2\end{array}\right)\left(\begin{array}{lll}1 & 0 & 1\end{array}\right)$ related to $\alpha \mathrm{Ti}$ phase in $2 \theta \approx 35.5^{\circ}, 38.3^{\circ}$ and $40.4^{\circ}$ were indexed in all experimental conditions. Small differences in $2 \theta$ position are due to nitrogen diffusion, which stays in the interstice of the titanium crystalline structure and changes its lattice parameter. The plan $\left(\begin{array}{lll}1 & 1 & 0\end{array}\right)$ associated with $\beta \mathrm{Ti}$, in $2 \theta \approx 39.5^{\circ}$, was also indexed at all experimental conditions. The characteristic peaks of $\alpha$ and $\beta$ Ti phases, indexed in positions very close in all experimental conditions, confirm that the surface treatment did not modify the substrate as regards the phases, grain size and texture.

The experimental condition PIII $-1200 \mathrm{~Hz}$ was the only one that showed characteristic peaks associated with oxides and nitrides (Fig. $4 \mathrm{~b}$ and c). $\mathrm{Ti}_{2} \mathrm{~N}$ is related to the plane $\left(\begin{array}{lll}1 & 0 & 1\end{array}\right)$ in $2 \theta=34.8^{\circ}$. The planes $(200)$ and $(220)$, in $2 \theta=42.1^{\circ}$ and $43.7^{\circ}$, respectively, are related to TiN. The position $2 \theta=43.7^{\circ}$ represents the summed contributions of $\mathrm{TiN}$ and $\mathrm{TiO}_{2}$. Finally, the peaks in $2 \theta=46.5^{\circ}, 47.5^{\circ}, 49.3^{\circ}$ and $49.9^{\circ}$ are not characteristic of any particular phase, but to a nonstoichiometric compound formed by $\mathrm{Ti}-\mathrm{N}-\mathrm{O}$. The latter compounds are present in environments where nitrogen and oxygen diffuse [11]. In the present work, the PIII chamber environment contained oxygen, despite vacuum and argon cleaning steps.

The PIII pulse parameters influence mechanical behavior of metal alloys in such a way that different pulse frequency and duration combinations act both on the composition and layer thicknesses. In this research, frequency was varied and pulse duration $(40 \mu \mathrm{s})$ was remained. Liu et al. [33] treated Ti-Ni alloy with nitrogen by PIII and used frequencies ranging from 50 to $200 \mathrm{~Hz}$ for orthopedic purposes. They concluded that in lower frequency $(50 \mathrm{~Hz})$, the treatments produced more stable surfaces in corrosive environment because they generate less residual thermal stresses. High frequencies result in higher operating temperatures and the heat increases the instability of the nitride layer, formed on surface, due to thermal stress [33]. Minto et al. [18] studied the fatigue behavior of AA7050 aluminum alloy, treated by PIII with nitrogen, varying the voltage parameters $(5-10 \mathrm{kV})$ and frequency $(100-1000 \mathrm{~Hz})$. They performed XRD, microhardness, microscopy, EDS and residual stress analysis of the different experimental conditions and related to the rotating bending fatigue behavior. The reported observations were that high frequencies increase the working temperature during treatment, increasing particles diffusion, residual oxygen implantation and particle coalescence. The effect on surface is a heterogeneous layer formation, with $\mathrm{AlN}$ and $\mathrm{Al}_{2} \mathrm{O}_{3}$, and hardness decreasing by particles coalescence. At low frequency condition, the temperature is lower $\left(100 \mathrm{~Hz}-117^{\circ} \mathrm{C}\right)$, with a nitride layer more uniform - since oxygen diffusion is less favored, the hardness values higher - because diffusion and consequent particle coalescence is diminished. Therefore, PIII treatments conducted at higher frequencies decreased fatigue resistance of aluminum alloy, although generating compressive residual stresses on surface. Finally, the authors observed that even if the voltage dropped, if the frequency increases, the fatigue resistance of aluminum alloy decreases, making the frequency parameter a predominant influence on microstructure and mechanical behavior [18]. Bonora et al. [17] treated 15-5PH stainless steel with nitrogen by PIII. The treatment conditions were $10 \mathrm{kV}, 1500 \mathrm{~Hz}$, pulse of $50 \mu \mathrm{s}$ and a working time of $2 \mathrm{~h}$. The PIII treated 15-5PH showed compressive residual stress of $-230 \mathrm{MPa}$, nanohardness equal to $12 \mathrm{GPa}$ with diffusion zone thickness of $500 \mathrm{~nm}$ and roughness of $270 \mathrm{~nm}$. The untreated condition presented values related with the above microstructural analysis equal to $36 \mathrm{MPa}, 5 \mathrm{GPa}$ and $143 \mathrm{~nm}$, respectively. When subjected to cyclic loading, fatigue resistance at $900 \mathrm{MPa}$ increased $44 \%$ and at $730 \mathrm{MPa}$ increased more than two times compared to the untreated condition [17].

It can be seen in the literature that the frequency influence of PIII treatment changes with the material and combination of roughness and residual stresses. Decrease in roughness and the presence of 

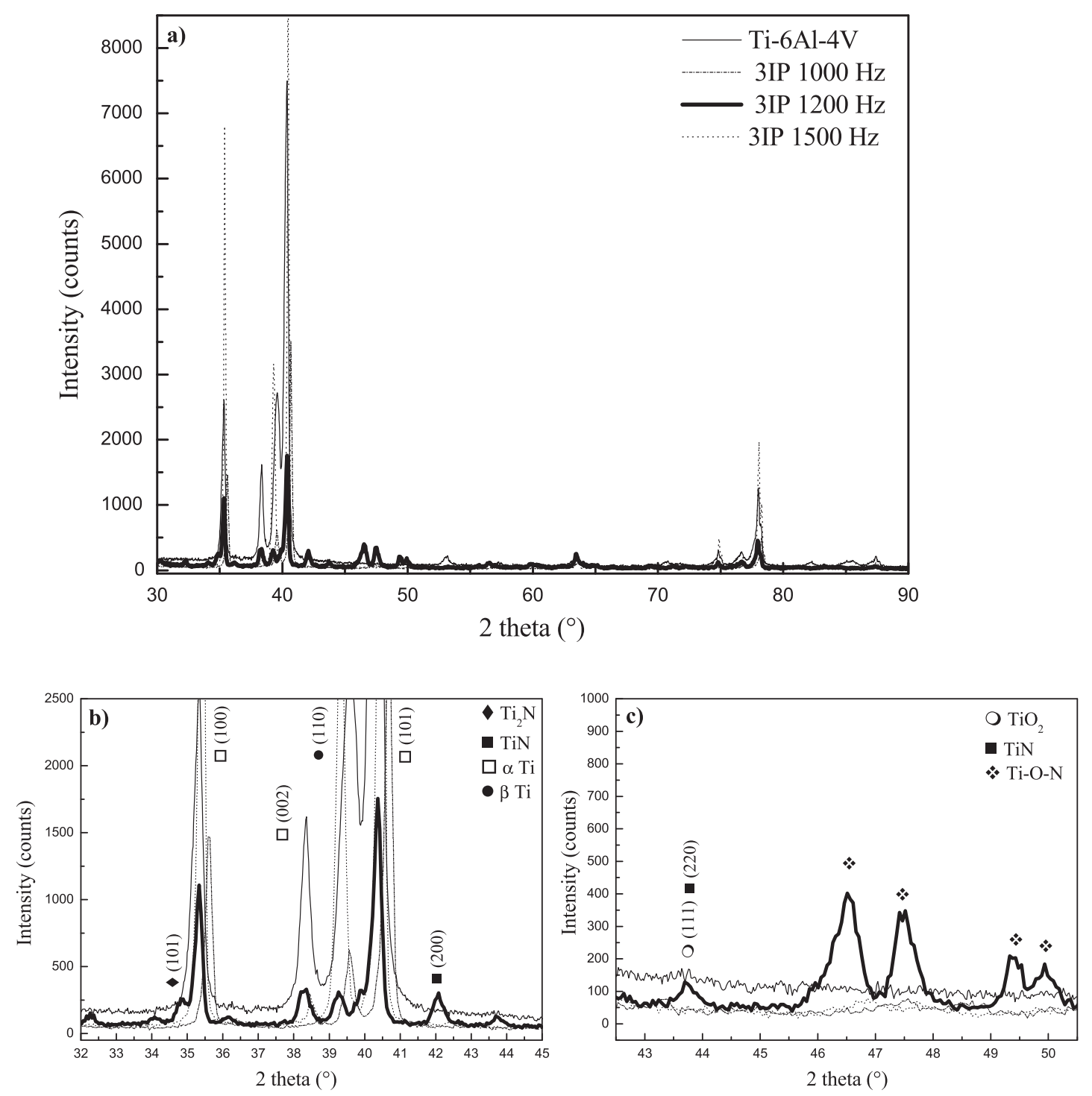

Fig. 8. Ti-6Al-4V XRD: untreated and PIII treated conditions, at frequencies of 1000, 1200 and $1500 \mathrm{~Hz}$.

compressive stresses on surface do not guarantee higher fatigue resistance to a metallic alloy $[17,18,33]$.

Additionally, it is known that the implantation process has a critical value, that above it, the microstructure must relieve the stress in the form of micro-deformation and micro-cracks [5]. Thus, diffusion-based treatments have an optimum condition that allowed the treated material to acquire a set of surface properties, added to the residual stress values, diffusion layer and chemical bonds type, capable of improving fatigue behavior of a metallic alloy.

In the present work, PIII treated Ti-6Al-4V alloy fatigue behavior can be explained as follows: PIII treatments did not form a protective ceramic layer on surface. If this happened, implanted nitrogen would accommodate in the interstices of the titanium matrix until a point of saturation is reached, and from this point, start to react and form nitrides, which would cover the metal surface [32]. For all experimental conditions of PIII treatment studied, nitrogen reacted with the titanium, but in shallow depths, without the formation of a detectable layer during microscopic analysis. All PIII experimental conditions increased the Ti-6Al-4V alloy surface roughness at levels ranging from $20 \%$ to $30 \%$, relative to untreated material.

Fig. 9 displays a comparison between each PIII treatment and untreated conditions. Increasing frequency of PIII treatment dropped fatigue resistance of Ti-6Al-4V alloy.
At $1000 \mathrm{~Hz}$, the treatment increased Ti-6Al-4V alloy superficial roughness, increasing stress concentrators points on the surface and decreasing fatigue resistance in comparison with the untreated Ti-6Al$4 \mathrm{~V}$ alloy by $22 \%$, for $10^{6}$ cycles. At $1200 \mathrm{~Hz}$, although higher surface roughness, it was observed nitride formation on surface. These nitrides compounds acted as hard particles, making difficult the crack nucleation and propagation during cyclic loading, the fatigue resistance diminished by $7.5 \%$ compared with untreated Ti-6Al-4V alloy. At $1500 \mathrm{~Hz}$, nitrogen implantation process exceeded a critical value and disfavored nitrogen and titanium reaction (XRD miss nitride formation). Furthermore, the stress level on surface, caused by nitrogen solubility in the crystalline structure of titanium, created micro-strain regions and pre-cracks necessary for crystal lattice relief. The fatigue resistance, when $f=1500 \mathrm{~Hz}$, decreased by $50 \%$ compared with untreated Ti-6Al-4V alloy.

Tables 4 and 5 present ratio $\sigma_{\text {treat }} / \sigma_{\text {untreat }}$ low and high cycle fatigue, respectively. The number of cycles for each case, in low and high regime, for different mechanical conditions of Ti-6Al-4V alloy and different surface treatments are also displayed. It is important to note that the ratio greater than 1 indicates resistance due to surface treatment.

An initial analysis of Table 4 and 5 shows that the case of PIII treatment with $f=1200 \mathrm{~Hz}$ resulted in the highest ratio $\sigma_{\text {treat }} / \sigma_{\text {untreat }}$ as represented in both tables. The worst condition was obtained for 

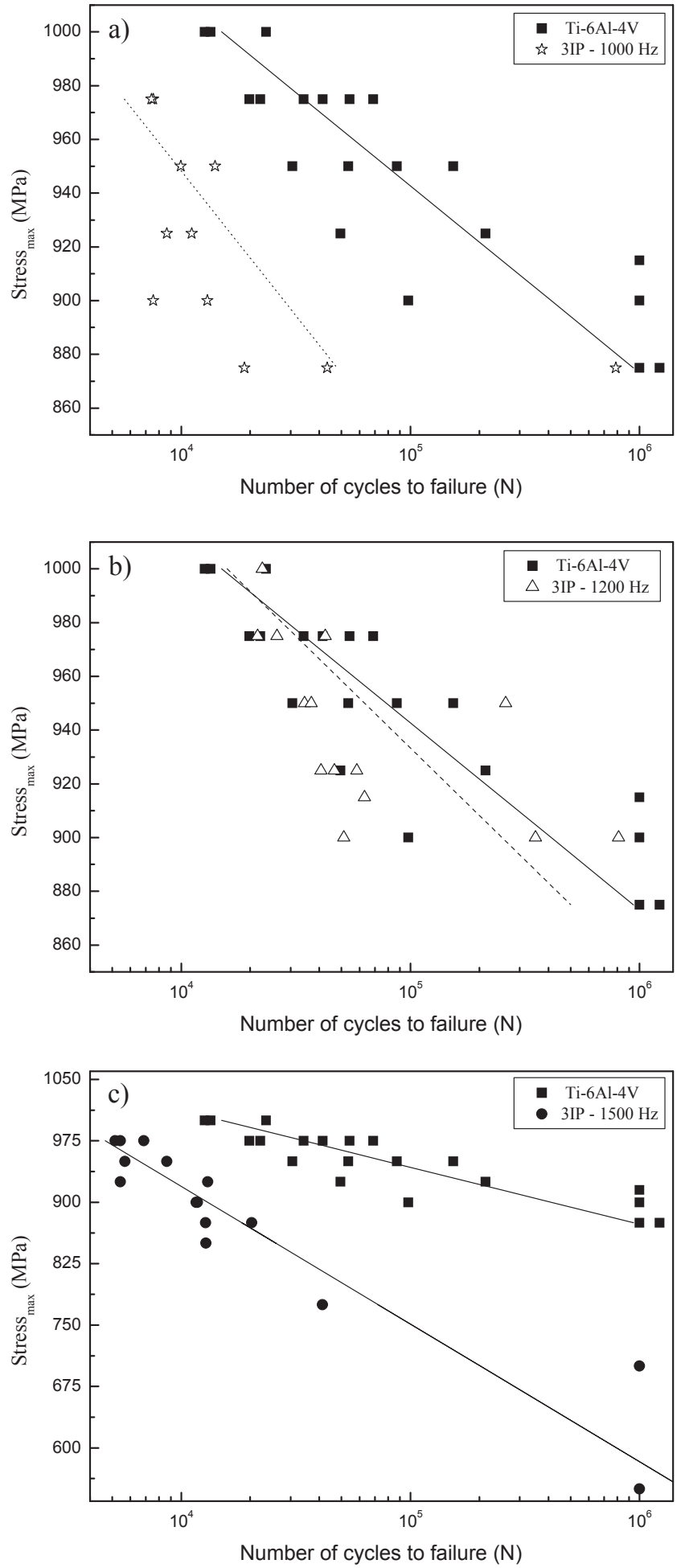

Fig. 9. Comparison between $\mathrm{S} \times \mathrm{N}$ curves of untreated and PIII treated conditions, at frequencies of: (a) 1000, (b) 1200 and (c) $1500 \mathrm{~Hz}$.

$f=1500 \mathrm{~Hz}$ and $f=1000 \mathrm{~Hz}$ remained between the conditions already mentioned. It was observed that for low and high cycle fatigue the experimental treatment conditions behaved differently in relation to the ratio $\sigma_{\text {treat }} / \sigma_{\text {untreat }}$ : for $f=1200$, the ratio $\sigma_{\text {treat }} / \sigma_{\text {untreat }}$ remained the same; for $f=1000$ and $1500 \mathrm{~Hz}$, the ratio $\sigma_{\text {treat }} / \sigma_{\text {untreat }}$ showed that the PIII treatment damage more the Ti-6Al-4V fatigue behavior in high cycle fatigue regime.

Tsuji et al. [34] studied the combined effect of plasma carburizing
Table 4

Average lifetime of surface treated Ti-6Al-4V alloy, low cycle fatigue: experimental data and literature reports.

\begin{tabular}{|c|c|c|c|}
\hline$\sigma_{\mathrm{ys}}(\mathrm{MPa})$ & Number of cycles $(\mathrm{N})$ & Treatment & $\sigma_{\text {treat }} / \sigma_{\text {untreat }}$ \\
\hline \multirow[t]{3}{*}{1000} & \multirow[t]{3}{*}{$1 \times 10^{4}$} & PIII - $1000 \mathrm{~Hz}$ & 0.94 \\
\hline & & PIII $-1200 \mathrm{~Hz}$ & 0.97 \\
\hline & & PIII - $1500 \mathrm{~Hz}$ & 0.88 \\
\hline \multirow[t]{2}{*}{1125} & \multirow[t]{2}{*}{$3 \times 10^{4}$} & Plasma carburizing [22] & 0.95 \\
\hline & & $\mathrm{PC}+\mathrm{SP}[22]$ & 1.15 \\
\hline 927 & $3 \times 10^{4}$ & Gas nitriding $^{\mathrm{a}}[23]$ & 0.86 \\
\hline 1180 & $1 \times 10^{4}$ & PVD [12] & 0.92 \\
\hline- & $2 \times 10^{4}$ & $\mathrm{PEO}^{\mathrm{b}}[24]$ & 0.83 \\
\hline
\end{tabular}

${ }^{a}$ Rotating bending fatigue test.

b Plasma electrolytic oxidation.

Table 5

Average lifetime of surface treated Ti-6Al-4V alloy, high cycle fatigue: experimental data and literature reports.

\begin{tabular}{|c|c|c|c|}
\hline$\sigma_{\mathrm{ys}}(\mathrm{MPa})$ & Number of cycles (N) & Treatment & $\sigma_{\text {treat }} / \sigma_{\text {untreat }}$ \\
\hline \multirow[t]{3}{*}{1000} & \multirow[t]{8}{*}{$1 \times 10^{7}$} & PIII - $1000 \mathrm{~Hz}$ & 0.78 \\
\hline & & PIII - $1200 \mathrm{~Hz}$ & 0.92 \\
\hline & & PIII - $1500 \mathrm{~Hz}$ & 0.50 \\
\hline \multirow[t]{2}{*}{1125} & & Plasma carburizing [22] & 0.93 \\
\hline & & $\mathrm{PC}+\mathrm{SP}[22]$ & 1.14 \\
\hline 927 & & Gas nitriding $^{\mathrm{a}}$ [23] & 1.09 \\
\hline 1180 & & PVD [12] & 0.50 \\
\hline- & & $\mathrm{PEO}^{\mathrm{b}}[24]$ & 0.60 \\
\hline
\end{tabular}

${ }^{\text {a }}$ Rotating bending fatigue test.

b Plasma electrolytic oxidation.

(PC) and shot peening (SP). The authors observed that the effect of plasma carburizing on specimen surface was the decrease of fatigue resistance in comparison of untreated Ti-6Al-4V alloy. On the other hand, experimental results in Tables 4 and 5 for the same surface treatment show an increase in the fatigue resistance due to the shot peening process. Interesting is to observe that for low and high cycle fatigue, the ratio $\sigma_{\text {treat }} / \sigma_{\text {untreat }}$ is very similar for plasma carburizing and PC + SP treatments [34]. Tokaji and coauthors [35] studied Ti-6Al-4V alloy fatigue behavior, when submitted to gas nitriding at $850^{\circ} \mathrm{C}$ for $4 \mathrm{~h}$. The authors reported that the nitride layer reduced fatigue strength due to its hardness and depth [35]. A larger area of the cross section is modified in a compound of greater hardness, which is more susceptible to crack propagation. Costa et al. [12] deposited TiN on Ti-6Al-4V alloy by PVD and concluded that PVD reduced fatigue strength in low and high cycle regime due to the presence of voids in the layer that act as crack sites. Apachitei and colleagues [36] studied fatigue properties of biofunctional coatings. They treated Ti-6Al-4V alloy by plasma electrolytic oxidation that built on the surface a microporous oxide coating. According to them, PEO layer damage Ti-6Al-4V alloy fatigue performance due to pre-existing stress concentrators such as pores and microcracks, besides loss of ductility imposed by the $\mathrm{TiO}_{2}$ ceramic layer [36].

Figs. 10 and 11 show fatigue fractures of untreated and PIII treated Ti-6Al-4V alloy at $950 \mathrm{MPa}$, respectively.

Cracks nucleated from the surface (indicated by arrows) when inclusions and/or particles are absent, which would act as stress concentrators within the sample. Nucleated cracks on the surface are indicative of plastic deformation during cyclic loading. Dislocations slip through extrusions and intrusions, which are normal to surface and present in grains on surface with crystallographic orientation favorable to slip [37]. According to Bridier et al. [38], slipping occurs preferentially in the basal and prismatic $\alpha$ phase planes. Authors reported higher slipping proportion in the Ti-6Al-4V alloy basal planes but they observed that cracks appear first and propagate faster because of prismatic planes slipping [38]. Titanium alpha phase present HC crystal 

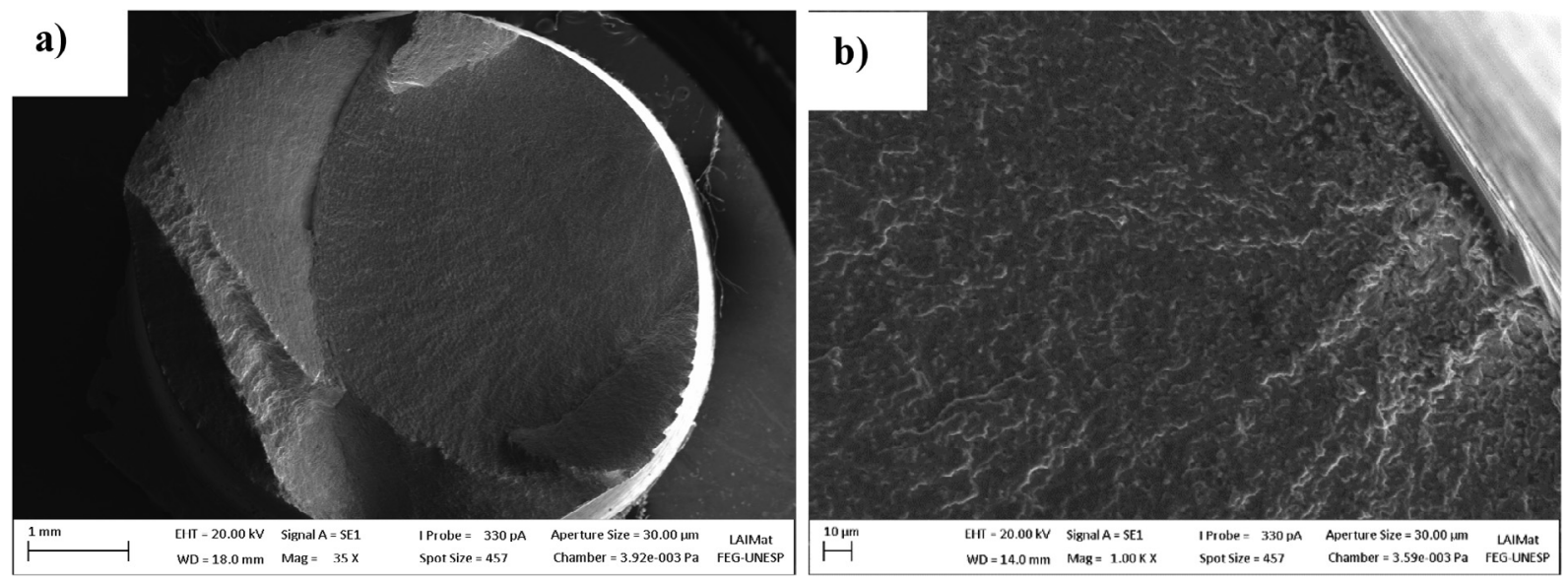

Fig. 10. Fatigue fractures of untreated Ti-6Al-4V alloy, at $950 \mathrm{MPa}$ (a) fracture overview, (b) crack nucleation detail.
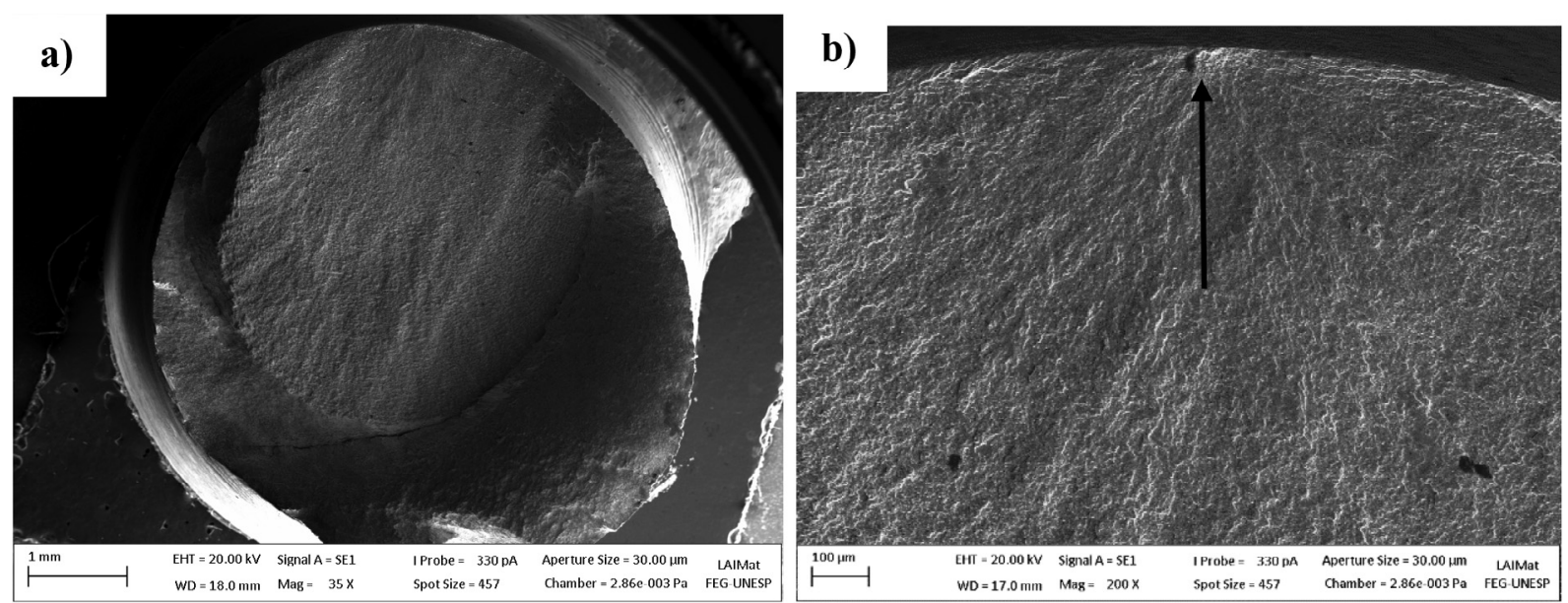

Fig. 11. Fatigue fractures of PIII treated Ti-6Al-4 V alloy, at $950 \mathrm{MPa}, f=1200 \mathrm{~Hz}$ : (a) fracture overview, (b) crack nucleation detail.

structure and slip systems are related to basal planes (0001), pyramidal and prismatic planes, all related to directions family $\{101 \overline{0}\}\{101 \overline{1}\}$ $\langle 112 \overline{0}\rangle[39]$.

Remembering that the failure mode, detected by Figs. 10 and 11 analyze, involves crack nucleation on surface and propagation stages; the fatigue behavior of PIII treated Ti-6Al-4V alloy in all experimental conditions can be explained as follows:

- for $f=1000 \mathrm{~Hz}$, the higher surface roughness accelerated the crack nucleation process;

- for $f=1200 \mathrm{~Hz}$, the nitrides acted as a barrier to the advance of the initial crack propagation;

- for $f=1500 \mathrm{~Hz}$, the distortion levels in the titanium lattice structure generated by nitrogen dissolution promoted pre-cracks that were already present before the fatigue tests. For this condition, therefore, there was no nucleation stage, only propagation.

Regarding the PIII treatments behavior in low and high cycle fatigue, it was observed that the difference in fatigue behavior observed mainly when $f=1500 \mathrm{~Hz}$ is related to the surface characteristics and microstructure influence on each regime. When in low cycle fatigue, due to high stress levels, the crack nucleation depends on the material resistance, ie its mechanical characteristics (hardness, yield strength, fracture toughness). When in high cycle fatigue, the stress levels are low and in many cases are unable to nucleate a crack in the material surface. At this point, the surface characteristics, and therefore the modification that a surface treatment generates on it, may cooperate or further hinder the nucleation process. Thus, a superficial treatment, when it has a negative effect, has its effect potentiated in a high cycle regime. This behavior is common in surface treatment of hard chromium on steel, where the thick chrome coating shows cracks in its cross section even before the fatigue process (pre-cracks) [40,41].

Therefore, PIII treatment combines the advantage of diffusion processes, which creates a region of intermediate hardness between the substrate and the ceramic layer, preventing crack propagation; and the plasma environment, which provides greater control of implantation and chemical reactions at lower temperatures. Finally, although the treatment has reduced fatigue life of Ti-6Al-4V alloy in the present work, this treatment shows less decrease in the fatigue resistance, when compared to conventional treatments [26,27].

\section{Conclusions}

Ti-6Al-4V alloy was PIII treated at $9.5 \mathrm{kV}, 380^{\circ} \mathrm{C}$ and varying frequencies between $1000 \mathrm{~Hz}$ and $1500 \mathrm{~Hz}$. The microstructural characteristics - dislocations mobility, strain fields in the crystalline lattice, ceramic compounds presence - changes Ti-6Al-4V alloy fatigue resistance. These characteristics are affected by the different combinations of PIII treatment parameters. DRX and XPS analysis showed the presence of $\alpha \mathrm{Ti}, \beta \mathrm{Ti}, \mathrm{TiN}, \mathrm{Ti}_{2} \mathrm{~N}, \mathrm{TiO}_{2}$ and a compound non-stoichiometric with composition of Ti-O-N. The nitrogen-based compounds were detected only at the condition where $f=1200 \mathrm{~Hz}$. The increased 
frequency results in increased collisions between nitrogen and surface, at the same time it contributes to increasing the strain fields in the crystallographic lattice of titanium alloy. Thus, there is a critical value, above it, is generated micro-strain and pre-cracks that were already present before the fatigue tests promoting only crack propagation. When $f=1200 \mathrm{~Hz}$, the combination of PII treatment parameters provided nitride formation on surface, hindering crack nucleation and propagation (of the order of some grains), increasing fatigue resistance of treated Ti-6Al-4V alloy when compared with the other two treatment conditions. It was found that PIII treatment is more advantageous than other surface treatments, such as HVOF or PVD, because it has less influence on the fatigue resistance loss, especially in the low cycle region.

\section{Acknowledgments}

The authors would like to acknowledge FAPESP (Fundação de Amparo à Pesquisa do Estado de São Paulo) and CNPq (Conselho Nacional de Desenvolvimento Científico e Tecnológico) for their continued financial support (Process FAPESP 2015/00331-2, CNPQ 303832/2014-2).

\section{References}

[1] Tian X, Chu PK. Modeling of the relationship between implantation parameters and implantation dose during plasma immersion ion implantation. Phys Lett A $2000 ; 277: 42-6$.

[2] Ueda M, Silva MM, Lepienski CM, Soares PC, Gonçalves JaN, Reuther H. High temperature plasma immersion ion implantation of Ti6Al4V. Surf Coatings Technol 2007;201:4953-6.

[3] Mello CB, Ueda M, Silva MM, Reuther H, Pichon L, Lepienski CM. Tribological effects of plasma immersion ion implantation heating treatments on Ti-6Al-4V alloy. Wear 2009;267:867-73.

[4] Castagnet M, Yogi LM, Silva MM, Ueda M, Couto aa, Reis DaP, et al. Neto, microstructural analysis of Ti-6Al-4V alloy after plasma immersion ion implantation (PIII). Mater Sci Forum 2012;727-728:50-5.

[5] Byeli AV, Shikh SK, Khatko VV. Friction and wear of high speed steel doped with low energy nitrogen ions. Wear 1992;159:185-90.

[6] de Oliveira VMCA, da Silva MCL, Pinto CG, Suzuki PA, Machado JPB, Chad VM, et al. Short-term creep properties of Ti-6Al-4V alloy subjected to surface plasma carburizing process. J Mater Res Technol 2015;4:359-66.

[7] Williamson DL, Davis JA, Wilbur PJ, Vajo JJ, Wei R, Matossian JN. Relative roles of ion energy, ion flux, and sample temperature in low-energy nitrogen ion implantation of Fe-Cr-Ni stainless steel. Nucl Instrum Method Phys Res B 1997;128:930-4.

[8] Rangel EC, Durrant SF, Rangel RCC, Kayama ME, Landers R, Nilson C. Amorphous carbon nitrogenated films prepared by plasma immersion ion implantation and deposition. Thin Solid Films 2006;515:1561-7.

[9] da Silva LLG, Ueda M, Silva MM, Codaro EN. Corrosion behavior of Ti-6Al-4V alloy treated by plasma immersion ion implantation process. Surf Coatings Technol 2007;201:8136-9.

[10] Silva MM, Ueda M, Pichon L, Reuther H, Lepienski CM. Surface modification of Ti6Al4V alloy by PII at high temperatures: effects of plasma potential. Instrum Method Phys Res Sect B Beam Interact Mater Atoms 2007;257.

[11] Oliveira VMCA, Vazquez AM, Aguiar C, Robin A, Barboza MJR. Materials science \& engineering a nitride coatings improve Ti-6Al-4V alloy behavior in creep tests. Materi Sci Eng: A 670 (2016) 357-368.

[12] Costa MYP, Cioffi MOH, Venditti MLR, Voorwald HJC. Fatigue fracture behavior of Ti-6Al-4V PVD coated. Procedia Eng 2010;2:1859-64.

[13] Yildiz F, Yetim aF, Alsaran a, Çelik a, Kaymaz I, Efeoğlu I. Plain and fretting fatigue behavior of Ti6Al4V alloy coated with TiAlN thin film. Tribol Int 2013;66:307-14.

[14] Qian J, Farokhzadeh K, Edrisy a. Ion nitriding of a near- $\beta$ titanium alloy: microstructure and mechanical properties, Surf Coatings Technol 2014:258:134-41.

[15] Lin YC, Chen HM, Chen YC. The effect of different methods to add nitrogen to titanium alloys on the properties of titanium nitride clad layers. Mater Des 2014;54:222-9.

[16] Ali N, Fulazzaky MA, Mustapa MS, Ghazali MI, Ridha M, Sujitno T. Assessment of fatigue and corrosion fatigue behaviours of the nitrogen ion implanted CpTi. Int J Fatigue 2014;61:184-90.

[17] Bonora R, Cioffi MOH, Voorwald HJC. Plasma immersion ion implantation on 15-5PH stainless steel: influence on fatigue strength and wear resistance. IOP Conf Series J Phys: Conf Series 2017;843:012023.

[18] Minto TA, Oliveira VMCA, Voorwald HJC. Plasma immersion ion implantation: Influence on the rotating bending fatigue strength of AA 7050-T7451 aluminum alloy. Int J Fatigue 2017;103:17-27.

[19] Campanelli SL, Casalino G, Mortello M, Angelastro A, Ludovico AD. Sciencedirect microstructural characteristics and mechanical properties of Ti6Al4V alloy fiber laser welds. Procedia CIRP 2015;33:428-33.

[20] Mahdipoor MS, Kevorkov D, Jedrzejowski P, Medraj M. Water droplet erosion behaviour of gas nitrided Ti6Al4V. Surf Coatings Technol 2016;292:78-89.

[21] Descostes M, Mercier F, Thromat N, Beaucaire C, Gautier-Soyer M. Use of XPS in the determination of chemical environment and oxidation state of iron and sulfur samples: constitution of a data basis in binding energies for Fe and S reference compounds and applications to the evidence of surface species of an oxidized pyrite in a carbonate medium. Appl Surf Sci 2000;165:288-302.

[22] Feng X, Sun M, Ma X, Tang G. Structure and tribological performance by nitrogen and oxygen plasma based ion implantation on Ti6Al4V alloy. Appl Surf Sci 2011;257:9904-8.

[23] Fouquet V, Pichon L, Straboni a, Drouet M. Nitridation of Ti6Al4V by PBII: study of the nitrogen diffusion and of the nitride growth mechanism. Surf Coatings Technol $2004 ; 186: 34-9$.

[24] Oktay S, Kahraman Z, Urgen M, Kazmanli K. XPS investigations of tribolayers formed on TiN and (Ti, Re)N coatings. Appl Surf Sci 2015

[25] Ismail IM, Abdallah B, Abou-Kharroub M, Mrad O. XPS and RBS investigation of TiN $\mathrm{xO}$ y films prepared by vacuum arc discharge. Instrum Methods Phys Res Sect B Beam Interact Mater Atoms 2012;271:102-6.

[26] Costa MYP, Voorwald HJC, Pigatin WL, Guimarães VA, Cioffi MOH. Evaluation of shot peening on the fatigue strength of anodized Ti-6Al-4V alloy. Mater Res 2006;01:107-9.

[27] Costa MYP, Venditti MLR, Voorwald HJC, Cioffi MOH, Cruz TG. Effect ofWC$10 \% \mathrm{Co}-4 \% \mathrm{Cr}$ coating on the Ti-6Al-4V alloy fatigue strength. Mater Sci Eng, A 2009;507:29-36.

[28] Haidyrah AS, Newkirk JW, Castaño CH. Weibull statistical analysis of Krouse type bending fatigue of nuclear materials. J Nucl Mater 2016;470:244-50.

[29] Ornaghi BP, Meier MM, Rosa V, Cesar PF, Lohbauer U, Braga RR. Subcritical crack growth and in vitro lifetime prediction of resin composites with different filler distributions. Dent Mater 2012;28:985-95.

[30] Sakin R, Ay İ. Statistical analysis of bending fatigue life data using Weibull distribution in glass-fiber reinforced polyester composites. Mater Des 2008;29:1170-81.

[31] Kustas FM, Misra MS, Wei R, Wilbur PJ, Knapp JA. High temperature nitrogen implantation of Ti-6AI-4V I: Microstructure characterization. Surf Coat Technol 1992;51:100-5.

[32] Jeong H, Lee Y, Lee D. Effects of pre-heat conditions on diffusion hardening of pure titanium by vacuum rapid nitriding. Surf Coat Technol 2017;326:395-401.

[33] Liu XM, Wu SL, Chu PK, Chung CY, Chu CL, Chan YL, et al. In vitro corrosion behavior of TiN layer produced on orthopedic nickel - titanium shape memory alloy by nitrogen plasma immersion ion implantation using different frequencies. Surf Coat Technol 2008;202:2463-6.

[34] Tsuji N, Tanaka S, Takasugi T. Effects of combined plasma-carburizing and shotpeening on fatigue and wear properties of Ti-6Al-4V alloy. Surf Coat Technol 2009;203:1400-5.

[35] Tokaji K, Ogawa T, Shibata H. The effects of gas nitriding on fatigue behavior in titanium and titanium alloys. J Mater Eng Perform 1999;8:159-67.

[36] Apachitei I, Leoni a, Riemslag aC, Fratila-Apachitei LE, Duszczyk J. Enhanced fatigue performance of porous coated Ti6Al4V biomedical alloy. Appl Surf Sci 2011;257:6941-4.

[37] Chan KS. Roles of microstructure in fatigue crack initiation. Int J Fatigue 2010;32:1428-47.

[38] Bridier F, Villechaise P, Mendez J. Slip and fatigue crack formation processes in an $\alpha / \beta$ titanium alloy in relation to crystallographic texture on different scales. Acta Mater 2008;56:3951-62.

[39] Balasubramanian S, Anand L. Plasticity of initially textured hexagonal polycrystals at high homologous temperatures: application to titanium. Acta Mater 2002;50:133-48.

[40] Voorwald HJC, Silva MP, Costa MYP, Cioffi MOH. Improvement in the fatigue strength of chromium electroplated AISI 4340 steel by shot peening. Fatigue Fract Eng Mater Struct 2009;32:97-104.

[41] Souza RC, Voorwald HJC, Cioffi MOH. Fatigue strength of HVOF sprayed $\mathrm{Cr}_{3} \mathrm{C}_{2}$ 25NiCr and WC-10Ni on AISI 4340 steel. Surf Coat Technol 2008;203:191-8. 